\title{
Outcomes of Cataract Surgery Complicated by Retained Lens Fragments Requiring Pars Plana Vitrectomy
}

This article was published in the following Dove Press journal: Clinical Ophthalmology

\author{
Weijie $V \operatorname{Lin}^{1, *}$ \\ Megan N Scott ${ }^{2,3, *}$ \\ Chosang Tendhar ${ }^{4}$ \\ Shazia $\mathrm{FAli}^{2,3}$ \\ Zaina Al-Mohtaseb ${ }^{2,3}$ \\ Rizwan Shaikh ${ }^{2,3}$ \\ Christina $Y$ Weng ${ }^{2,3}$ \\ 'School of Medicine, Baylor College of \\ Medicine, Houston, TX, USA; ' 2 Department \\ of Ophthalmology, Baylor College of \\ Medicine, Houston, TX, USA; ${ }^{3}$ Ben Taub \\ General Hospital, Harris Health System, \\ Houston, TX, USA; ${ }^{4}$ Office of Research, \\ Assessment and Planning, Adelphi \\ University, New York, NY, USA \\ *These authors contributed equally to this \\ work
} where procedures are performed by trainees. January 2010 and January $2016(\mathrm{~N}=20)$.
Objective: To analyze outcomes and complications related to cataract surgery complicated by retained lens fragment (RLF) requiring pars plana vitrectomy (PPV) in a county hospital

Methods: Retrospective study of consecutive patients who met inclusion criteria and underwent PPV for RLF in the vitreous cavity at an urban teaching hospital between

Main Outcomes/Measures: Visual acuity was recorded pre- and post-operatively over a follow-up period of 3 to 12 months. Complications and patient factors contributing to outcomes were assessed using paired and unpaired t-tests and multiple linear regression.

Results: The average rate of cataract surgery with RLF requiring PPV was $0.75 \%$. Twenty patients met inclusion criteria. Mean pre-operative visual acuity (VA) was logMAR 1.7 (Snellen 20/1000). Nearly half (8/20) had nuclear cataracts grade $3+$ or higher. The majority $(14 / 20)$ had factors predisposing them to cataract surgery complications. Most patients underwent PPV within 1 week (median 6.5 days). At 12-month follow-up, significant $(\mathrm{p}=0.001)$ visual acuity (VA) improvement from initial VA was observed, with final mean $\log$ MAR $0.6( \pm 0.75$; Snellen 20/80) and median $\operatorname{logMAR} 0.35$ (Snellen 20/45). Nearly half of the patients had a final Snellen VA $\geq 20 / 40$. Factors associated with less VA improvement were older age and greater proportion of lens dropped $(\mathrm{p}<0.01)$. Complications following PPV included hypotony (5 patients), corneal edema (4), elevated intraocular pressure (IOP) (3), and cystoid macular edema (3).

Conclusions/Relevance: Despite patients with advanced pathology and trainee surgeons, rates of cataract surgery-associated RLF requiring PPV at a large tertiary care teaching hospital are similar to reported rates in the literature.

Keywords: trainee, complicated cataract surgery, retained lens fragments, resident, fellow, pars plana lensectomy, pars plana vitrectomy, teaching, surgical education

\section{Introduction}

Cataract surgery is the most frequently performed surgical procedure in the world, with an estimated 19-20 million surgeries done annually. ${ }^{1,2}$ This number continues to rise as a result of the aging population and expansion of ambulatory surgical facilities. $^{3-5}$ While the risk of intraoperative complications related to cataract surgery is quite low with modern surgical approaches and technology, it does exist. One such complication is posterior capsule rupture with "dropped" lens particles into the vitreous cavity. ${ }^{6}$ The reported incidence of intravitreal retained
Correspondence: Christina Y Weng Department of Ophthalmology, Baylor College of Medicine, MBA Alkek Eye Center 1977 Butler Blvd., 3rd Floor, Houston, Texas 77030, USA

$\mathrm{Tel}+1$ 713 798-6100

Email christina.weng@bcm.edu 
lens fragments (RLF) ranges from $0.1 \%-1.5 \%{ }^{7-13}$ Rupture of the posterior lens capsule is estimated to significantly increase the risk of post-operative endophthalmitis by four- to ten-fold. ${ }^{14}$ Furthermore, this complication often requires a subsequent pars plana vitrectomy with lens fragment retrieval or pars plana lensectomy (collectively referred to as PPV from this point forward), although some cases can be managed medically. ${ }^{12,15-17}$ Nevertheless, post-operative visual outcomes are relatively good with $44-65 \%$ of affected patients achieving a visual acuity of $20 / 40$ or better. ${ }^{10,17-19}$ The ideal timing (early versus late) of vitrectomy is a subject of debate, and studies have yielded mixed or inconclusive results. ${ }^{19-21}$ One systematic meta-analysis of 27 studies concluded that vitrectomy should be performed 3-7 days post-cataract surgery, with the first two days reserved for recovery. ${ }^{12}$

In this study, we seek to evaluate surgical outcomes of patients who underwent PPV for RLF at a public teaching hospital in Houston, Texas. Although outcomes of vitrectomy for RLF have been evaluated as aforementioned, to the authors' knowledge, no studies have yet been conducted in the focused setting of a public teaching hospital where the vast majority of surgeries are performed by trainees. Analysis on this specific cohort of patients carries significance for two reasons. First, the patient population in public teaching hospitals often presents with more advanced disease, has more comorbidities, and faces socioeconomic barriers which challenge patient compliance. All of these could presumably increase the rate of intraoperative complications or negatively impact postoperative outcomes. Second, studies have corroborated that increased surgeon experience correlates with reduced complication rates. ${ }^{7,8,22}$ Therefore, we sought to examine whether trainees (residents and fellows) would have complication rates and outcomes comparable to those of more experienced surgeons.

\section{Methods}

This retrospective study was conducted at Ben Taub General Hospital (BTGH) in Houston, Texas, a large tertiary referral and public teaching hospital that is affiliated with Baylor College of Medicine. Records of all phacoemulsification cataract surgeries (CEIOL) performed between January 2010January 2016 were identified using CPT (Current Procedural Terminology) codes 66850, 66852, 66840, ICD (International Classification of Diseases)-9 code 998.82, and ICD-10 code H59.029. All cases that subsequently required PPV for RLF were included, while cases with retained lens material due to trauma or those managed solely with anterior segment surgery (e.g., anterior vitrectomy) were excluded. Patients with fewer than three months of follow-up data post-PPV were excluded. All surgical cases were primarily performed by facultysupervised PGY (post-graduate year)-3 and PGY-4 ophthalmology residents, PGY-5 cornea/refractive fellows (who performed the CEIOL), or PGY-6 surgical retina fellows (who performed the PPV). While specific patient management was surgeon-dependent, many patients received an injection of subconjunctival dexamethasone, were started on oral or intravenous acetazolamide, and were treated with topical steroids in the post-cataract period.

Patient demographics and pre-operative (both preCEIOL and pre-PPV), peri-operative, and post-operative measures for each case were recorded. Primary outcome measured was best-corrected logMAR visual acuity (VA) at the final timepoint, defined as the most recent measurement available in the record at least three months post-PPV and at most twelve months post-PPV. Secondary outcomes included post-operative complications. Unpaired and paired t-tests were conducted to identify differences in mean outcomes. A multiple linear regression model that incorporated eight independent continuous and dummy variables of preoperative and peri-operative datapoints (age, gender, Hispanic race, history of intraocular intervention, comorbid hypertension, fraction of lens dropped, days between CEIOL and PPV, NSC (nuclear sclerotic cataract) grade) was utilized to predict the dependent variable of overall VA change. Statistical significance was defined as a p-value of $<0.05$.

This study was approved by the institutional review boards of Baylor College of Medicine, the University of Texas Health Science Center at Houston, and the Harris Health System; it complied with the tenets of the Declaration of Helsinki and the Health Insurance Portability and Accountability Act.

\section{Results}

Within the study period, over 400 cataract surgeries were performed at BTGH annually; of these, 1-4 cases of RLF required PPV each year. On average, the annual incidence of RLF requiring PPV was $0.75 \%$. A total of twenty consecutive eyes of twenty patients were included in this study.

\section{Pre-Operative data}

Patient demographic information is summarized in Table 1. Mean age was 61.9 years (range 12 to 81 years), 55\% of patients were male, and the majority $(60 \%)$ identified as Hispanic/Hispanic American. A significant proportion of this cohort had systemic comorbidities (e.g., diabetes 
Table I Demographic, Pre-Operative, Post-Operative Characteristics

\begin{tabular}{|c|c|}
\hline Characteristic: & $\begin{array}{l}\text { Number of } \\
\text { Patients (\%): }\end{array}$ \\
\hline $\begin{array}{l}\text { Age: } \\
\qquad 50 \text { years } \\
\text { 50-60 years } \\
61-70 \text { years } \\
71-80 \text { years } \\
>80 \text { years }\end{array}$ & $\begin{array}{l}3(15 \%) \\
3(15 \%) \\
8(40 \%) \\
5(25 \%) \\
1(5 \%)\end{array}$ \\
\hline $\begin{array}{l}\text { Ethnicity: } \\
\text { Hispanic } \\
\text { African American } \\
\text { Asian } \\
\text { Caucasian }\end{array}$ & $\begin{array}{l}12(60 \%) \\
4(20 \%) \\
1(5 \%) \\
3(15 \%)\end{array}$ \\
\hline $\begin{array}{l}\text { Gender: } \\
\text { Male } \\
\text { Female }\end{array}$ & $\begin{array}{l}\text { II (55\%) } \\
9(45 \%)\end{array}$ \\
\hline $\begin{array}{l}\text { Cataract Properties***: } \\
\text { Significant nuclear component }(\geq 3+) \\
\text { Significant posterior subcapsular } \\
\text { component }(\geq 3+\text { or sheet) } \\
\text { Mixed nuclear and subcapsular } \\
\text { Moderate nuclear component }\end{array}$ & $\begin{array}{l}8(47 \%) \\
3(17.6 \%) \\
2(11.8 \%) \\
4(23.5 \%)\end{array}$ \\
\hline $\begin{array}{l}\text { Comorbidities*: } \\
\text { Diabetes mellitus } \\
\text { Hypertension } \\
\text { Hyperlipidemia } \\
\text { Chronic kidney disease } \\
\text { Coronary artery disease } \\
\text { Congestive heart failure } \\
\text { Cancer } \\
\text { Depression }\end{array}$ & $\begin{array}{l}12(63.2 \%) \\
14(73.7 \%) \\
11(57.9 \%) \\
2(10.5 \%) \\
2(10.5 \%) \\
2(10.5 \%) \\
1(5.3 \%) \\
4(21.1 \%)\end{array}$ \\
\hline $\begin{array}{l}\text { Prior Ocular History*: } \\
\text { Vitrectomy } \\
\text { Retinal detachment } \\
\text { Pseudoexfoliative syndrome } \\
\text { Panretinal photocoagulation } \\
\text { Uncontrolled glaucoma }\end{array}$ & $\begin{array}{l}4(22.2 \%) \\
3(16.7 \%) \\
2(11.1 \%) \\
3(16.7 \%) \\
2(11.1 \%)\end{array}$ \\
\hline $\begin{array}{l}\text { Post-cataract Surgery Complications**: } \\
\text { Corneal edema } \\
\text { Elevated IOP } \\
\text { Hypotony } \\
\text { Anterior chamber inflammation } \\
\text { Cystoid macular edema } \\
\text { Retinal tear/detachment }\end{array}$ & $\begin{array}{l}\text { I }(5.6 \%) \\
\text { II (6I.1\%) } \\
\text { I ( }(5.6 \%) \\
7(38.9 \%) \\
2(11.1 \%) \\
2(11.1 \%)\end{array}$ \\
\hline $\begin{array}{l}\text { Post-vitrectomy Complications**: } \\
\text { Corneal edema } \\
\text { Elevated IOP }\end{array}$ & $\begin{array}{l}4 \text { (22.2\%) } \\
3 \text { (16.7\%) }\end{array}$ \\
\hline
\end{tabular}

(Continued)
Table I (Continued).

\begin{tabular}{|l|l|}
\hline Characteristic: & $\begin{array}{l}\text { Number of } \\
\text { Patients (\%): }\end{array}$ \\
\hline Hypotony & $5(27.8 \%)$ \\
Anterior chamber inflammation & $3(16.7 \%)$ \\
Cystoid macular edema & $3(16.7 \%)$ \\
\hline
\end{tabular}

Notes: *, **, *** Excluded I, 2, 3 patients, respectively, due to lack of recorded data.

mellitus) or ocular comorbidities (e.g., prior vitrectomy (4) or pseudoexfoliative syndrome (2)). Nearly half (40\%) of patients had nuclear cataracts of grade $3+$ (scale of 1-4) or that were designated as brunescent or white. Additionally, several patients were affected by other factors that predisposed them to cataract surgery complications, such as axial length $>25 \mathrm{~mm}$ (4), alpha-blocker medication use (1), or known zonular compromise (2).

The mean pre-CEIOL VA was logMAR 1.7 (Snellen VA equivalent of 20/1000); median was logMAR 1.5 (Snellen 20/630), and range was logMAR 0.3-3.0 (Snellen 20/40HM). $40 \%$ of patients had hand motion VA. Lens drop occurred during the phacoemulsification phase in $84 \%$ of cases. Fraction of lens dropped was 1 (entire lens) in 39\% of cases, with the average being $0.70(70 \%$ of the lens volume). Anterior vitrectomy was performed in 14/20 patients. 11/20 patients were left aphakic, 7 had a sulcus IOL, and 2 had an IOL placed in the capsular bag. Mean cataract surgery duration was 68 mins, with $56 \%$ of cases lasting between 60 and 90 mins.

The mean post-CEIOL/pre-PPV VA was logMAR 1.4 (Snellen 20/500), with median VA logMAR 1.2 (Snellen 20/320) (Figure 1). The median time lapse between CEIOL to PPV was 6.5 days, with a range of 0 to 113 days and one outlier at 3166 days. Timing of vitrectomy was not significantly associated with age, prior ocular history, or post-cataract complications.

In the interim period between CEIOL and PPV, patients experienced a variety of complications such as corneal edema (1), ocular hypertension (11, defined as intraocular pressure (IOP) $>21 \mathrm{~mm} \mathrm{Hg}$ ), hypotony (1), anterior chamber inflammation (7), cystoid macular edema (2), or retinal tear/ detachment (2) (Table 1).

\section{Intraoperative Data}

Lens fragment removal was performed using the fragmatome in $95 \%$ of cases. In addition to pars plana vitrectomy with 


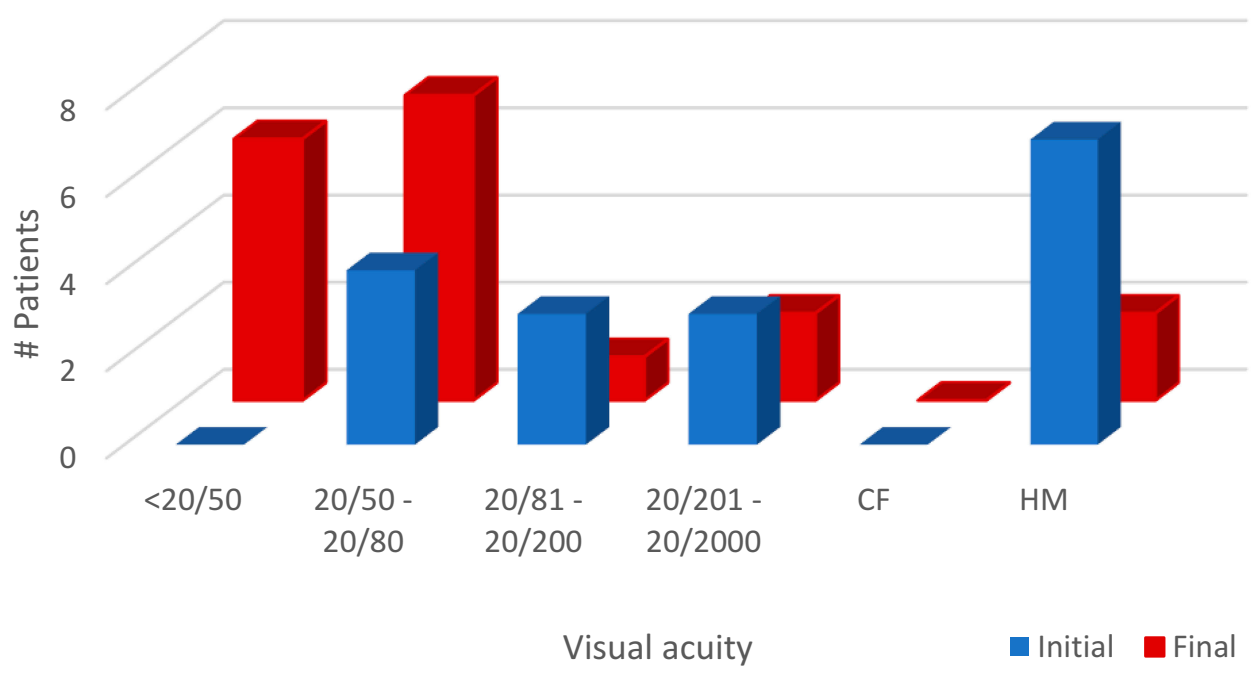

Figure I Initial and Final VA Distributions. Distribution of Snellen visual acuity measurements, comparing pre-cataract surgery (initial) and final follow-up (final).

RLF removal, concurrent procedures were performed in some cases: secondary intraocular lens (IOL) implantation in 4 cases, endolaser in 3 cases (for retinal tear or for prophylaxis), endolaser with gas tamponade in 3 cases ( 2 retinal tears, 1 localized retinal detachment), and endolaser with silicone oil tamponade in 1 case for retinal detachment. The differences in pre-PPV and intraoperative PPV retinal tear rates are addressed later. Of note, two patients had secondary IOLs placed in the post-PPV period, but before the final VA was measured. Five patients were aphakic at the final VA timepoint; most had been fitted with an aphakic contact lens.

\section{Post-Operative Data}

Significant improvement in vision from pre-cataract VA to VA at final follow-up $(\mathrm{p}=0.005)$ was observed (Figure 2). From a baseline pre-cataract VA average of $\log$ MAR 1.7
(Snellen 20/1000), mean improvement from pre-cataract VA was $-0.2 \log$ MAR units at 1 week, $-0.7 \log$ MAR units at 1 month, $-0.9 \log$ MAR units at 3 months, and -1 $\operatorname{logMAR}$ units at 6 months post-PPV. Average final bestcorrected visual acuity was logMAR 0.6 (Snellen 20/80), median was $\operatorname{logMAR} 0.35$ (Snellen 20/45), and range was logMAR 0.0-3.0 (Snellen 20/20-HM). Median follow-up period was 324 days following PPV.

Multiple linear regression analysis (assuming fixed weights) revealed that certain factors were associated with the overall change in visual acuity. Older age (coefficient of $-0.037)$ and fraction of lens dropped (-2.67) were associated with less VA improvement $(\mathrm{p}<0.01)$. An increased initial cataract grade was significantly associated with greater VA improvement (coefficient of 1.071), likely due to worse initial pre-cataract VA.



Figure 2 Mean Visual Acuity Over Study Period. Mean logMAR visual acuity of all patients for whom data was available at time points: initial pre-cataract surgery; postcataract surgery/pre-PPV; post-operative day I (PODI); post-operative week I (POWI); post-operative months (POM) I, 3, 6, and final. 
Post-PPV complications include corneal edema (4), ocular hypertension (3), hypotony (5), anterior chamber inflammation (3), and cystoid macular edema (3) (Table 1). Most of these were transient and 50\% resolved within the first month post-PPV. Hypotony (defined as $<5 \mathrm{~mm} \mathrm{Hg}$ ) was noted to be the most common complication, although there was a statistically significant association between decreased IOP and acetazolamide (Diamox) administration post-cataract extraction, which remained significant even when glaucoma patients were excluded. T-tests of post-PPV complications did not show any significant association with final VA outcomes. Hypotony seemed to correlate with poorer final VA (mean final VA $\operatorname{logMAR} 1.08 \pm 1.12$ with hypotony vs 0.53 \pm 0.87 without hypotony), although this finding did not reach statistical significance.

\section{Discussion}

This study aimed to evaluate the outcomes of residentperformed cataract surgery requiring PPV for RLF in the setting of a large county hospital. Interestingly, the rate of RLF is similar to those reported from non-teaching hospitals where the surgeries are performed by experienced surgeons $(0.75 \%$ compared with $0.1-1.5 \%) .^{7-12}$ This differs from other studies that have suggested that the incidence of RLF is likely increased for less experienced surgeons. ${ }^{7,8}$ However, in contrast to those studies, these studies focused on inexperienced surgeons in a training environment while supervised by skilled surgeons. The rate of post-PPV complications is comparable to rates described in previous studies including corneal edema (22\% compared with 20-50.8\%), cystoid macular edema (17\% compared with 6-27\%), and retinal detachment $(0 \%$ compared with $0-12 \%$ ) (Table 2). It should be noted that the studied patient population was younger with higher rates of prior ocular interventions $(45 \%)$ or other potentially complicating comorbidities $(65 \%)$ compared to those included in similar studies. Thus, these results are especially encouraging for teaching hospitals, as they suggest that even with occurrence of post-cataract surgery complications in cases performed by trainees, visual outcomes are ultimately quite good. However, these findings are not intended to understate the sequelae of a cataract surgery complicated by RLF, which includes subsequent surgery, additional resources (e.g., time, cost, medications), and potential limitations in visual prognosis.

Timing between CEIOL and PPV in cases with RLF has long been a topic of debate. ${ }^{7,12,20}$ While the majority of patients in this study underwent PPV within one week of CEIOL, there were large variations. In this study, we did not find that the inter-surgery time lapse correlated with final visual outcomes or complication rates. Notably, two patients had a diagnosed retinal tear or detachment post-CEIOL/pre-PPV, and two other patients had a retinal tear or detachment found intraoperatively during the PPV (and one was unclear as to when the detachment occurred). Delay in PPV for RLF was not associated with a greater incidence of retinal tear or detachment, but these observations emphasize the importance of careful retinal surveillance post-cataract and intraoperatively during the vitrectomy. Variables that did seem to be associated with poorer VA outcomes include older age and larger fraction of lens dropped.

One distinct finding of this study was the low frequency of post-operative elevated IOP (17\% compared to rates of $46 \%$ $100 \%$ in the literature). In contrast, hypotony was observed more often ( 5 cases). This may be related to our institutional surgeon practice of administering prophylactic oral acetazolamide in cases where there are retained lens fragments. Doing so may blunt post-operative IOP elevation or even lead to an apparent hypotony. Another possible explanation for the observed hypotony is ischemia of the ciliary body which can result from multiple intraocular surgeries, especially if there were pre-existing ocular comorbidities.

Strengths of this study include its use of longitudinal data that provides patient details which span the entire perioperative course. As this was a retrospective study, it is limited by the historical medical record from which the data were extracted. Thus, any errors or omissions in the record have the potential of being incorporated into this analysis. Additionally, it should be noted that 5 patients were aphakic at the time their final VA was recorded; while several of them did undergo an aphakic contact lens fitting, this still may have negatively impacted VA measurements.

While not a direct comparison, the outcomes in this cohort of patients with complicated cataract surgery can be discussed alongside a study previously published at our institution with a similar patient and trainee surgeon population, reporting on overall outcomes and complication rates of cataract surgery from January 2012 to June $2015 .^{23}$ In that study, the rate of intraoperative or post-operative complications was $14.0 \% .^{23}$ A dropped nucleus was seen in 8 cases, representing $0.6 \%{ }^{23}$ Furthermore, visual outcomes in that study at the post-operative month one visit were reported as average Snellen 20/32 overall and average Snellen 20/46 in cases with complications. ${ }^{23}$ These complication rates are similar to our findings. As expected, a worse average visual 


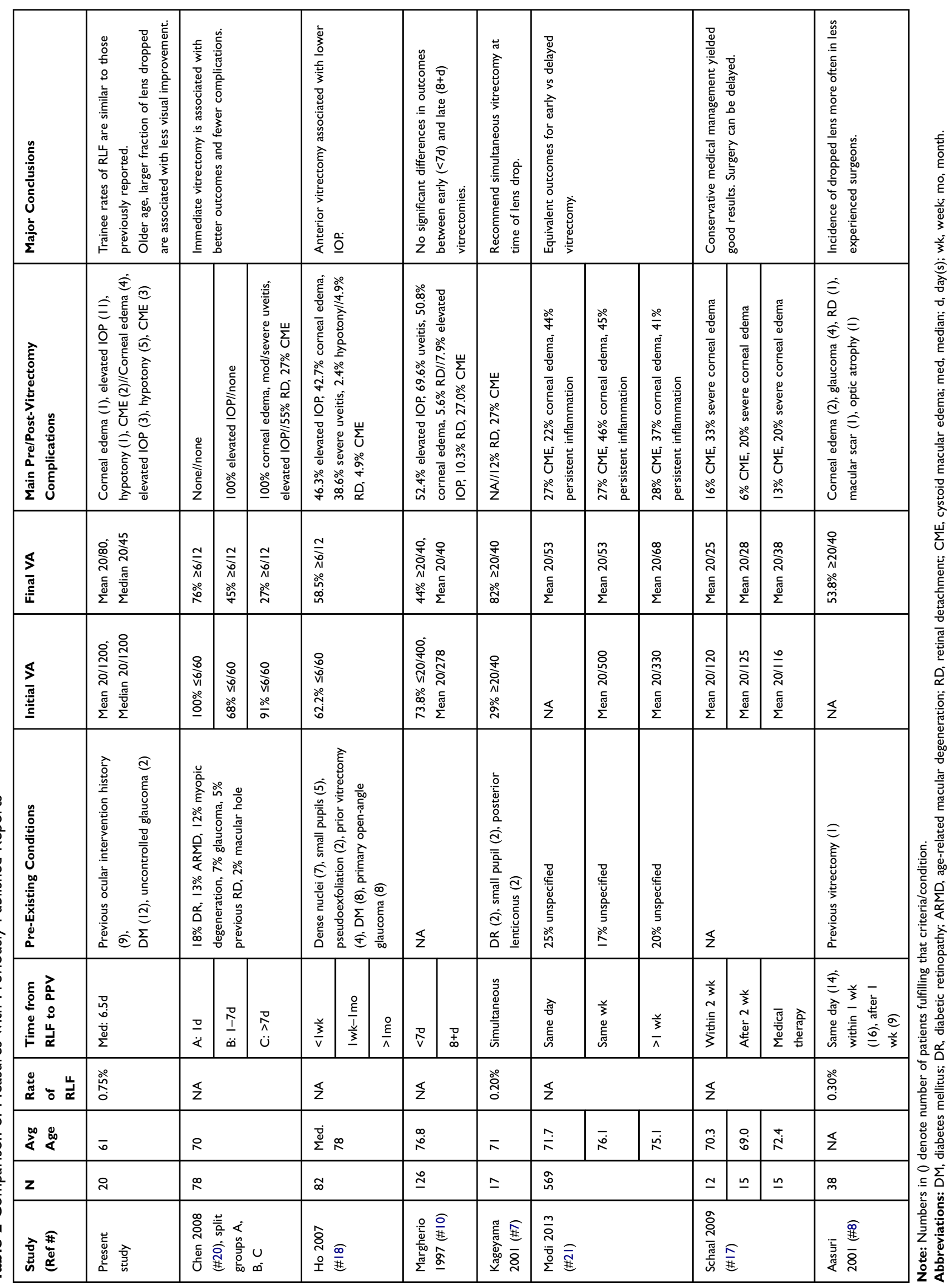


acuity and a longer recovery period are seen in our study cohort, presumably due to posterior involvement and second surgical intervention.

This analysis showed that despite multiple factors that could limit outcomes for patients who undergo complicated cataract surgery in a public teaching hospitaltrainee-level surgeons, ocular and systemic comorbidities, more advanced presenting pathology-ultimately, VA outcomes were relatively good (average Snellen 20/80 and median 20/45) and comparable to reported outcomes for similar cases performed by nontrainee surgeons. ${ }^{8,10,21}$ This is consistent with several recent studies which have demonstrated similar complication rates and outcomes, when comparing trainees and attendings at academic centers. ${ }^{24,25}$ However, the recovery period was prolonged, with the majority reaching significant VA improvement only after post-operative month three. While some did experience post-operative complications, most of these resolved within the first month after PPV, and the majority had no significant impact on final visual acuity. Time lapse between cataract surgery and pars plana vitrectomy did not have an apparent effect on visual outcomes or complication rates, although large variability in inter-surgery time span and the limited sample size should be taken into consideration.

Rates of cataract surgery-associated RLF requiring PPV at a large tertiary care teaching hospital are similar to published rates in the literature, despite patients with advanced pathology and trainee surgeons in this setting. Although their recovery period may be prolonged, these patients ultimately benefit from significant visual gains and demonstrate outcomes that are comparable to those reported for similar procedures performed by non-trainee surgeons.

\section{Acknowledgments}

No financial support was utilized in carrying out this study.

\section{Author Contributions}

All authors contributed to data analysis, drafting and revising the article, gave final approval of the version to be published, and agree to be accountable for all aspects of the work.

\section{Disclosure}

Dr Christina Y Weng reports personal fees from Alcon, Inc., Allergan, Inc., Alimera Sciences, Inc., outside the submitted work. The authors report no other conflicts of interest in this work.

\section{References}

1. Wang W, Yan W, Fotis K, et al. Cataract surgical rate and socioeconomics: a global study. Invest Ophthalmol Vis Sci. 2016;57 (14):5872-5881. doi:10.1167/iovs.16-19894

2. Schein OD, Cassard SD, Tielsch JM, Gower EW. Cataract surgery among Medicare beneficiaries. Ophthalmic Epidemiol. 2012;19 (5):257-264. doi:10.3109/09286586.2012.698692

3. French DD, Margo CE, Behrens JJ, Greenberg PB. Rates of routine cataract surgery among medicare beneficiaries. JAMA Ophthalmol. 2017;135:163. doi:10.1001/jamaophthalmol.2016.5174

4. Pascolini D, Mariotti SP. Global estimates of visual impairment: 2010. Br J Ophthalmol. 2012;96(5):614-618. doi:10.1136/bjophthalmol-2011-300539

5. Donaldson KE, Braga-Mele R, Cabot F, et al. Femtosecond laser-assisted cataract surgery. J Cataract Refract Surg. 2013;39 (11):1753-1763. doi:10.1016/j.jcrs.2013.09.002

6. Yorston D, Gurung R, Hennig A, et al.. Cataract complications. Community Eye Health. 2008;21(65):1-3.

7. Kageyama T, Ayaki M, Ogasawara M, Asahiro C, Yaguchi S. Results of vitrectomy performed at the time of phacoemulsification complicated by intravitreal lens fragments. Br J Ophthalmol. 2001;85 (9):1038-1040. doi:10.1136/bjo.85.9.1038

8. Aasuri MK, Kompella VB, Majji AB. Risk factors for and management of dropped nucleus during phacoemulsification. $J$ Cataract Refract Surg. 2001;27(9):1428-1432. doi:10.1016/S0886-3350(01) 00784-2

9. Pande M, Dabbs TR. Incidence of lens matter dislocation during phacoemulsification. J Cataract Refract Surg. 1996;22(6):737-742. doi:10.1016/S0886-3350(96)80313-0

10. Margherio RR, Margherio AR, Pendergast SD, et al. Vitrectomy for retained lens fragments after phacoemulsification. Ophthalmology. 1997;104(9):1426-1432. doi:10.1016/S01616420(97)30120-1

11. Mahmood S, von Lany H, Cole MD, et al. Displacement of nuclear fragments into the vitreous complicating phacoemulsification surgery in the UK: incidence and risk factors. Br J Ophthalmol. 2008;92 (4):488-492. doi:10.1136/bjo.2007.113936

12. Vanner EA, Stewart MW. Vitrectomy timing for retained lens fragments after surgery for age-related cataracts: a systematic review and meta-analysis. Am J Ophthalmol. 2011;152(3):345-357 e343. doi:10.1016/j.ajo.2011.02.010

13. Jaycock P, Johnston RL, Taylor H, et al. The cataract national dataset electronic multi-centre audit of 55,567 operations: updating benchmark standards of care in the United Kingdom and internationally. Eye (Lond). 2009;23(1):38-49. doi:10.1038/sj.eye.6703015

14. Cao H, Zhang L, Li L, Lo S. Risk factors for acute endophthalmitis following cataract surgery: a systematic review and meta-analysis. PLoS One. 2013;8(8):e71731. doi:10.1371/journal.pone.0071731

15. Bessant DA, Sullivan PM, Aylward GW. The management of dislocated lens material after phacoemulsification. Eye (Lond). 1998;12 (Pt 4):641-645. doi:10.1038/eye.1998.161

16. Ross WH. Management of dislocated lens fragments after phacoemulsification surgery. Can J Ophthalmol. 1996;31(5):234-240.

17. Schaal S, Barr CC. Management of retained lens fragments after cataract surgery with and without pars plana vitrectomy. $J$ Cataract Refract Surg. 2009;35(5):863-867. doi:10.1016/j.jcrs.2008.12.030

18. Ho SF, Zaman A. Clinical features and outcomes of pars plana vitrectomy in patients with retained lens fragments after phacoemulsification. $J$ Cataract Refract Surg. 2007;33(12):2106-2110. doi:10.1016/j. jcrs.2007.07.037 
19. Scott IU, Flynn HW Jr., Smiddy WE, et al. Clinical features and outcomes of pars plana vitrectomy in patients with retained lens fragments. Ophthalmology. 2003;110(8):1567-1572. doi:10.1016/ S0161-6420(03)00488-3

20. Chen CL, Wang TY, Cheng JH, Tai MC, Lu DW, Chen JT. Immediate pars plana vitrectomy improves outcome in retained intravitreal lens fragments after phacoemulsification. Ophthalmologica. 2008;222 (4):277-283. doi:10.1159/000139953

21. Modi YS, Epstein A, Smiddy WE, Murray TG, Feuer W, Flynn HW Jr. Retained lens fragments after cataract surgery: outcomes of same-day versus later pars plana vitrectomy. Am J Ophthalmol. 2013;156(3):454-459 e451. doi:10.1016/j.ajo.2013.04.038

22. Bell CM, Hatch WV, Cernat G, Urbach DR. Surgeon volumes and selected patient outcomes in cataract surgery: a population-based analysis. Ophthalmology. 2007;114(3):405-410. doi:10.1016/j. ophtha.2006.08.036
23. Clarke C, Ali SF, Murri M, et al. Outcomes and complication rates of primary resident-performed cataract surgeries at a large tertiary-care county hospital. J Cataract Refract Surg. 2017;43(12):1563-1570. doi:10.1016/j.jcrs.2017.09.025

24. Chen X, Zafar S, Sikder S, et al. National survey and outcomes of resident-performed cataract surgery in monocular patients in the United States. J Cataract Refract Surg. 2019;45(7):939-945. doi:10.1016/j.jcrs.2019.02.018

25. Low SAW, Braga-mele R, Yan DB, El-defrawy S. Intraoperative complication rates in cataract surgery performed by ophthalmology resident trainees compared to staff surgeons in a Canadian academic center. $J$ Cataract Refract Surg. 2018;44(11):1344-1349. doi:10.1016/j.jcrs. 2018.07.028
Clinical Ophthalmology

\section{Publish your work in this journal}

Clinical Ophthalmology is an international, peer-reviewed journal covering all subspecialties within ophthalmology. Key topics include: Optometry; Visual science; Pharmacology and drug therapy in eye diseases; Basic Sciences; Primary and Secondary eye care; Patient Safety and Quality of Care Improvements. This journal is indexed on PubMed

Submit your manuscript here: https://www.dovepress.com/clinical-ophthalmology-journal

\section{Dovepress}

Central and CAS, and is the official journal of The Society of Clinical Ophthalmology (SCO). The manuscript management system is completely online and includes a very quick and fair peer-review system, which is all easy to use. Visit http://www.dovepress.com/ testimonials.php to read real quotes from published authors. 